DE DE GRUYTER

OPEN

DOI 10.1515/pesd-2015-0023

PESD, VOL. 9, no. 2, 2015

\title{
E-WASTE IN BANGLADESH: EVALUATING THE SITUATION, LEGISLATION AND POLICY AND WAY FORWARD WITH STRATEGY AND APPROACH
}

\author{
Mahbub Alam ${ }^{1}$, Khalid Md. Bahauddin ${ }^{2}$
}

Key words: E-waste, Bangladesh, Policy, Strategy and Approach.

\begin{abstract}
Electronic waste (e-waste) is one of the fastest-growing pollution problems worldwide given the presence if a variety of toxic substances which can contaminate the environment and threaten human health, if disposal protocols are not meticulously managed. In Bangladesh almost 2.7 million metric tons of e-waste generated per year. Of this amount only 20 to 30 percent is recycled and the rest of the waste is released in to landfills, rivers, drains lakes, canals, open spaces which are very hazardous for the health and environment. Since Bangladesh is in the stream of rapid technological advancement, it is seldom to take necessary steps to avoid the future jeopardized situation because of e-waste. The current practices of e-waste management in Bangladesh suffer from a number of drawbacks like the difficulty in inventory, unhealthy conditions of informal recycling, inadequate legislation and policy, poor awareness and reluctance on part of the corporate to address the critical issues. The paper highlights the associated issues and strategies to address this emerging problem, analyses the policy and its gaps. Therefore, this paper also suggest that e-waste policy development may require a more customized approach where, instead of addressing e-waste in isolation, it should be addressed as part of the national development agenda that integrates green economy assessment and strategic environmental assessment as part of national policy planning. Finally this work also suggests some alternative strategies and approaches to overcome the challenges of e-waste.
\end{abstract}

\section{Introduction}

E-waste - waste from electronic and electrical equipment is a rapidly growing market, with 72 billion tons estimated to be generated annually worldwide by 2017. Obviously, the digital (r)evolution has resulted in a

\footnotetext{
${ }^{1}$ Department of Environmental Sciences, Jahangirnagar University, Bangladesh.

2 International Society for Development and Sustainability, Japan, ${ }^{2}$ Corresponding author: khalid.bahauddin@gmail.com
} 
significant increase in the quantity of e-waste but the quality of the waste has also changed with the use of hazardous substances. With massive growth of electronics and hardware sector, the demand of the electronics products has been enhanced manifold. Faster change of features in the electronics devices and availability of the improved products forcing the consumers to dispose the electronics products rapidly. This has caused generation of e-waste alarmingly.

Like other parts of the world, Bangladesh is also facing serious crisis due to growing generation of e-waste. The main challenge in Bangladesh is to create awareness of the environmental, social and economic aspects of e-waste among the public, consumers, producers, institutions, policy makers and legislators. It is observed in recent years that large volume of e-waste is being exported from western countries to Asian countries for disposal. It seems the recycling business in western countries is becoming economically non-viable due to rising cost of manpower and availability of input materials for running the plant in full capacity. The western countries are, therefore, compelled to find out alternative destinations for disposal, where the labour cost is comparatively low and the environmental laws are not enforced so strictly.

$\mathrm{E}$-waste is hazardous in nature due to presence of toxic substances like $\mathrm{Pb}$, $\mathrm{Cr} 6, \mathrm{Hg}, \mathrm{Cd}$ and flame retardants (polybrominated biphenyls and polybrominated diphenylethers etc.). E-waste disposal mixed with solid municipal waste is posing a greater threat for environmental degradation in the developing countries like Bangladesh, where formal recycling technology is not available and non-formal operators are extracting precious metals through crude means for easy money. The extraction of metals in nonformal units is carried out by dipping printed circuit board (PCBs) in the acidic/alkaline solutions and heating/burning of PCB. These processes are harmful to the workers and to the environment, which are the major concern of e-waste management in developing countries like Bangladesh.

While the human rights and environmental concerns emanating from the trans-boundary movements of toxic wastes and hazardous products have attracted considerable attention from scholars, activists, governments, and multilateral organizations such as the United Nations, the relatively newer dimension to this problem relates to electronic wastes otherwise referred to as 'e-wastes' in trendy parlance, which has received paltry scholarly attention thus far. Apart from urging a reconceptualisation of the electronic waste dimension to the global waste challenge in regulatory and trade terms, the underpinning thrust of this essay is that developing countries should find pragmatic ways of handling electronic waste because of their often toxic and hazardous substances that pollute the environment, expose people to diseases, and invariably violate a whole range of human rights. 


\section{Global Situation of E-waste}

In the 1990s, governments in the European Union (EU), Japan, the United States (US) and some other industrialized countries began to tighten the regulatory framework against electronic wastes and simultaneously commenced the setting up of electronic waste retrieval and recycling systems. However, not all industrialized countries had the capacity to deal with the steep quantity of the electronic and electrical wastes they generated.

Consequently, therefore, such industrialized countries began exporting their predicament to developing countries where laws to protect workers and the environment are non-existent, inadequate or unenforced. It was also cheaper to 'recycle' waste in developing countries, as for instance, the cost of breaking down or recycling of electronics in the US is 26 times more than the cost in Nigeria. In this most populous African country, labour costs are much lower while safety and environmental regulations are ignored or corruptly negotiated. Krueger described the general scenario this way: 'in the late 1980s the average disposal cost for one tone of hazardous waste in Africa was between \$US2.50 and \$US50, while in the OECD it ranged from \$US100 to \$US2000.' Electronic waste (or 'e-waste') is the term used to cover all types of electrical and electronic equipment that has or could enter the waste stream. Although electronic waste is a general term, it has assumed technical usage as a term covering any household or business item with circuitry or electrical components with power or battery supply. These may consist of electrical and electronic equipment and accessories that are non-operational or whose life cycles are extinguished. Obsolete electrical and electronic equipment include computers, televisions, audiovisual recorders, mobile phones, printers and other electronic goods such as air conditioners, electronic toys, washing machines, sewing machines, lawn mowers, elevators, kitchen equipment, therapeutic equipment, surveillance equipment, mobile radio transmitters, refrigerators, and their accessories. Although China and India used to be the 'dumping grounds' for such discarded global electronic wastes, several studies have exposed illegal exporting of electronic wastes from developed countries to African countries, and several Asian and Pacific countries, over the past few decades. Further levels of internally generated electronic wastes are rising across the developing world as well, a result of increased electronic goods consumption stemming, inter alia, from upward indices of material wealth in the so-called Third World countries.

Understandably, while the age of information superhighway has brought about many benefits, rising consumption of electrical and electronic equipment coupled with increasingly rapid obsolescence due to unrelenting technological advances, and diminishing product lifetimes has led to significant increases in 
global electronic wastes levels. Although exact data are difficult to come by because of the often clandestine nature of the trans-boundary movements of toxic wastes and hazardous products, researchers estimate that some 50 million tones of electronic waste is produced annually around the world, of which only ten percent is recycled. The UNEP study of 2009 warns that by 2020 , electronic waste in South Africa and China will have soared by 200-400 percent from 2007 levels and by 500 percent in India. Statistics also suggest that the United Kingdom alone is responsible for producing some 1 million tons per year of electronic wastes while the United States dumps between 300 and 400 million electronic items per year, and yet, less than twenty percent of those electronic wastes are properly recycled. This mounting crisis is compounded by low recycling rates, and illegal trans-boundary movement from developed to developing countries. At the same time, there is a significant increase in demand for electrical and electronic equipment from within developing countries, thus further contributing to future potential increases in electronic wastes.

Individual demand for electrical and electronic equipment is rising at a considerable pace across developing countries, driven primarily by growing disposable incomes and the quest for the monetary values of components retrieved from obsolete electrical and electronic equipment. Empirical studies show that because discarded electronics contain precious materials such as copper, gold and silver, many informal recycling yards have sprung up in developing countries where workers are paid low wages to extract these valuable metals from these waste products. Demand in the poorer countries of Africa and Asia for electronic waste has steadily grown as informal scrap yards found they could extract valuable substances such as copper, iron, silicon, nickel and gold, during the recycling process. A mobile phone, for example, is 19 percent copper and eight percent iron.

Despite this growing demand for, and saturation rates of, electronic and electrical equipment across the African continent, many people are unable to afford new electronic devices. The resultant quest for cheaper second-hand electrical and electronic equipment, coupled with low labour costs for reparation and refurbishment, has thus led to a strong electronic re-use market in developing countries, and is clearly strong across much of the developing world.18 Taking Nigeria as case study, for instance, the Standards Organization of Nigeria (SON) declared that within the first quarter of 2010 alone, it destroyed over 30 container shipments estimated at three hundred million Naira (approximately two million US dollars). Ghana is reported to have imported 31,400 metric tons of used electrical appliances in 2010 alone, 75 percent more than what was imported in 2009, with the United Kingdom accounting for more than half the quantum of imports into that country. In Tanzania, the World Bank 
asserts that over the last decade, personal computer penetration rates has risen ten-fold, while the number of people who own mobile phones has increased by over a hundred percent. Furthermore, reports commissioned by the Sustainable Electronic Wastes Project (StEP), a UN initiative that facilitates multimodal responses to the electronic wastes problem, indicate that electronic and electrical equipment markets remain unsaturated, particularly for ICT products, across the majority of the countries surveyed, indicating further future growths in electronic and electrical equipment penetration across the developing world. This scenario is assuredly going to result in higher levels of domestic electronic wastes generation annually, due to the reduced lifespan of second-hand electrical and electronic equipment.

As would be expected, a substantial portion of the demand for second-hand electrical and electronic equipment in the developing world is met by discarded equipment from government agencies and companies. In Kenya, for example, this source stream of electrical and electronic equipment was found to contribute up to twenty percent of the stock of second-hand ICT equipment in the country as of 2009. Much of the remaining demand for secondhand electrical and electronic equipment in developing countries is met by imports from developed countries. However, estimates from Greenpeace International, an independent international non-governmental organization that acts to transform attitudes and actions in order to protect and conserve the environment and to promote peace indicate that between 25 and 75 per cent of second-hand electrical and electronic equipment imported into Africa arrived in an unusable condition, beyond repair. In summing up this segment, it becomes discernible that the electronic waste problem is a global concern because of the nature of the generation, distribution and dumping of wastes in the globalised world economy.

While it is hard to calculate overall amounts of electronic wastes, it is beyond question that hefty quantities end up at locations where dispensation takes place at very rudimentary levels. This engenders concerns in relation to capacity building, resource efficiency and also the shorter and longer term apprehensions about the perils to human beings and the environment. Certainly, there is a lengthy and often complex sequence of processes in the electronic waste menace, starting from an idea that an info-tech expert has conceived for making a new invention, then the fabrication of that product, leading to its commercialization, procurement and, ultimately, it's dumping by the consumer after the product's life span or usefulness. These are the issues that throw up the questions around waste management beyond its confinement as a legal issue simpliciter. 


\section{Status of E-waste in Bangladesh}

Bangladesh is developing with the increasing of technology usage. Sustainable and safe use of technology is a big challenge for Bangladesh. The wastes from electronic goods come to Bangladesh as curse. People consume and dump the useless products without any consideration of environmental damages and sustainability. Moreover, every year significant number of scrap ships is imported to Bangladesh by importer legally and/illegally. These ships are broken in ship breaking yard located mainly in southern part of Bangladesh. During ship breaking, many heavy metals and toxic pollutants emit to environment and oil spills to land and water bodies. As Bangladesh has binding to import scrap ships, thus illegal import and trade off of e-waste is happening by importer to make profit and hence, e-waste vulnerability of Bangladesh is increasing. The scrap ships are carrying large volume of toxics products and electrical \& electronic waste, includes: antiques, barometers, clothes irons, electronics, lamps/light bulbs, light switches, paint(Latex), pesticides, television sets, thermometers, mirrors, washing machines, calculators, desktop liquid crystal display(LCD) monitors, laptop, LCD monitors, neon lights, sewer pipes, etc.

In Bangladesh almost 2.7 million metric tons of e-waste generated per year. According to yearly generation figures, it is clear that ship breaking yard occupied highest (2.5 million metric tons) position. Wastes from television sets have taken the second highest ( 0.182 million metric tons) position with an exponentially increasing rate. Bangladesh is one of the highly e-waste generating countries in the world. In Bangladesh about 2.7 million metric tons of e-waste has generated per year, in contrast, it is stated in the report "From ewaste to Resource" that in the world volume of e-waste generated per year is 20 million metric tons. However, according to UNEP projections, an estimated 2050 million tons of e-Waste is being generated annually in the world. No inventory has been made to assess the extent of e-waste problem in Bangladesh.

The goods bellow generates e-wastes in Bangladesh;

- Total number of PCs, TVs and Refrigerators in the year 2006 was $600,000,1,252,000$ and 2,200,000.

- The total number of TV sets users is roughly 10.3 million at the end of the year 2008.

- Every year around 59, 85,000 TV sets become scrape and generated $88,357.14$ metric tons of e-waste.

- The total number of mobile phone active subscribers in Bangladesh was 58.36million at the end of May 2010.

- Each year more than 2.8 million tons of electronic waste (it includes ewaste from 'ship breaking 'yard ) generated in Bangladesh. 
- E-waste generated from ship breaking yards about 2.5 million metric tons in a year.

- POPs: from ship breaking sites, PCB, Dioxin, Furan

- 10,504 metric tons of toxic e-waste by cell phone sets within last 21 years.

- Within the last 10 years IT sector generated 35,000 metric tons of ewaste in Bangladesh

According to an estimate, more than 500 thousand computers were in use in 2004 and this number has been growing at 11.4 per cent annually. Even if the figure of 500 thousand were taken as the baseline, that many PCs would contain approximately 15.323 tons of waste $(\% 27.2 \mathrm{~kg} / \mathrm{PC}$ for 5 year obsolescence) in 2010 containing deadly plastics, lead, mercury etc. The quantity of e-waste (PC and Cell phone) to be generated has been estimated by following two methods suggested in. The first method, Market Supply Method A. (MA) assumes that the average lifetime of an electronic product is approximately five years and after that these are discarded and come to the waste stream. The second method, Market Supply Method B (MB) assumes that all the products are not disposed at the same time; rather they are disposed in varying quantities over successive years. Here weighted average method is used to show the product disposal trend. For PCs the growth rate is considered to be 11.4 per cent and for cell phones a $100 \%$ growth rate is considered annually.

\section{Transboundary Issues of E-waste: Social and Legal Concern}

The demand for used electrical and electronic equipment within developing countries runs in tandem with the demand for non-serviceable or near end-of-life products. Although the exportation of second-hand electrical and electronic equipment is legal in many developing countries like Bangladesh, the exportation of electronic wastes is generally prohibited under international and regional treaty as well as under the statutes of several countries. Nevertheless, transboundary shipments of electronic wastes occur due to costly environmental and social standards for electronic wastes recycling in, for example, European Union (EU) countries, the US and Japan. Against the backdrop of the 'Not-In-My-Back-Yard (NIMBY)' syndrome, for instance, waste disposal facilities are shrinking in most industrialized countries as a result of stricter environmental regulation, yet, such wastes are ending up as illegal shipments which are effectively liberating developed countries of the electronic wastes problem, at the expense of the human residents in the recipient developing world. 
When the problem of this so called electronic wastes 'dumping' began to gain attention, it was Bangladesh who were one of the main receivers. In recent times, however, studies are finding that such shipments were being exported beyond Asia to some African countries, with high volumes received by Bangladesh, Ghana and Nigeria in particular. The scale of these illegal transboundary shipments of electronic wastes is growing; estimates from 2010 indicate that 40 percent of electronic wastes from Europe alone are being exported to Asia and Africa. In Nigeria, for example, estimates of the number of computer imports found to be non-functioning range from 75 to 95 per cent of each shipment. Not a few commentators have identified the growing phenomenon of hazardous and electronic wastes dumping in developing countries like Bangladesh from the industrialized world as a direct consequence of economic globalisation. While globalization has indeed being identified as transforming trade, finance, labour, migration, technology, communication, and governance, there can be no shying away from the reality that one of its negative collateral effects since the 1990s has been the reduction in the power of national governments in the face of global free market and technological advancements that have taken their regulation out of the reach of many governments.

While international economic and financial integration is rapidly occurring as a result of increased trade and capital, technology and information flows, the production and sale of consumer goods vis-á-vis up-to-date technology is heavily and disproportionately weighed against developing countries. And even though technological diffusion and advances in communications are occurring quite rapidly, very vast portions of the developing world are left out. This is the sort of atmosphere that leaves the developing world in the dire strait of incapacity to outrightly and effectively uproot the menace of dumping of wastes within their respective jurisdictions.

Although celebrated as the offshoot of the free market system that has characterized economic and trade liberalization since the 1990s, the commodification of waste, whether legal or illegal, cannot be 'free trade' in the fullest sense, but smacks of some form of oppression - predation, exploitation, or coercion - unquestionably translating the so-called economic liberation theory of free market and globalization into nightmarish experiences for environmental and human rights protection in developing countries like Bangladesh. Environmental justice theorists have extended the philosophical issues here by contending that treating others fairly also involves recognizing their membership in the moral and political community, promoting the capabilities needed for their functioning and flourishing, and ensuring their inclusion in political decision-making. Moreover, they maintain that 
distribution, recognition, capabilities, and participation are interrelated and interdependent - one can therefore not pursue one dimension of justice in isolation. Other writers have posited that within the context of toxic waste dumping, those who end up living closest to dumping sites and thus bearing the greatest adversities of toxic wastes are the poor, the homeless, street children and other vulnerable people at the lowest rungs of society. This reality manifests the deeper social problem of the environmental injustices that serve as catalysts for the human rights violations associated with the dumping of wastes.

\section{Environment, Health and Human Right Concern of E-waste}

Several scholars across geo-cultural divides have argued that linking human rights with environmental issues creates a rights-based platform to environmental protection that places the people harmed by environmental degradation or pollution at its centre. The articulation of the rights of human beings thus creates the opportunity to secure those rights through juridical bodies at the international and domestic fora. This has particular implications for those human groups that are most vulnerable to environmental harm and least able to access political remedies within their own meager means. The connectivity between human rights and the environment reveals that human rights abuses often lead to environmental harm, just as environmental degradation or pollution often causes egregious human rights violations. With more than one hundred national constitutions recognizing and protecting the right to a safe, clean and healthy environment, and virtually all international and regional human rights treaty monitoring bodies also recognizing the direct linkage between environmental harm and human rights norms, it is safe to posit that interjecting the electronic waste discourse from a rights-based perspective at this juncture is neither out of place nor abstract. In her seminal work produced on behalf of the World Health Organization in 2002, Shelton had proffered sweeping validation for the inclusion of a rights-based approach to every discourse on environmental health in the following words:

First, the emphasis on rights of information, participation, and access to justice encourages an integration of democratic values and promotion of the rule of law in broad-based structures of governance. Experience shows better environmental decision-making and implementation when those affected are informed and participate in the process: the legitimacy of the decisions exercises a pull towards compliance with the measures adopted. Another benefit of a rights-based approach is the existence of international petition procedures that allow those harmed to bring international pressure to bear when governments lack the will to prevent or halt severe pollution that threaten 
human health and well-being. In many instances, petitioners have been afforded redress and governments have taken measures to remedy the violation.

In other instances, however, the problem appears to be the result of a combination of governmental lack of capacity and lack of political will. The pollution may be caused by powerful enterprises whose business and investment are important to the state or the state may have inadequate monitoring systems to ensure air or water quality. Even in these instances, however, petition procedures can help to identify problems and encourage a dialogue to resolve them, including by the provision of technical assistance.

The non-functioning computers that arrive into most developing countries i.e. Bangladesh are sold as scrap, smashed up and discarded, a common practice within electronic wastes receiving countries that often lack capacity in the handling and recycling of the hazardous materials within the electronic wastes. Instead, manual dismantling, open burning to recover materials, and open dumping of residual fractions occurs. In Bangladesh, this is predominantly carried out by some disorganized informal and very few formal electronic wastes recycling sector. Consequently, relatively more hazardous material is introduced into informal electronic wastes burning and dumping grounds across many developing countries like Bangladesh, with higher implications for the environment and human health.

Electronic wastes present severe environmental and health challenges for the country saddled with the task of processing them, by reason of both the quantity and inherent dangers of toxicity. Electronic wastes can contain more than a thousand assorted substances, many of which are lethal. These may be in form of heavy metals or chemicals such as mercury, lead, cadmium, chromium, magnetic properties and antimony (flame retardants), including polybrominated biphenyls, polyvinyl chloride, polychlorinated biphenyls, and polybrominated diphenyl ethers. Perhaps the most hazardous components of electronic wastes are the mercury-containing components, batteries, printed circuit boards, CRTs, and the plastics which contain the brominated flame retardants. Accidental leakages and evaporation of these substances occur at the electronic wastes dumping sites, and results in the contamination of surrounding natural resources including, soil, crops, water, livestock and fish. Empirical studies at ship yard of Chittagong, Bangladesh revealed lead, mercury, cadmium, arsenic, antimony trioxide, polybrominated flame retardants, selenium, chromium, and cobalt contents in soil samples at rates far higher than average. Of course, when the electronic wastes are burnt, further toxic substances can be inadvertently generated. Beyond the environmental degradation concerns, the hazardous materials found in electronic wastes pose a significant risk to human health. After all, empirical research has established that people who break electronic 
wastes open often suffer radiation, nausea, headaches, respiratory failure among other health problems. However, it is not only the people working directly with electronic wastes who are susceptible to their harmful effects but also people living in the ambience of the waste dumps, and those indirectly affected through resulting contamination of the food chain, soils and rivers.

These people are exposed to the hazardous substances through dermal exposure, dietary intake, dust inhalation or particle intake, with the latter two sources found to be particularly significant. Other expert studies state that exposure to chemicals from e-waste - including lead, cadmium, mercury, chromium and polybrominated biphennyls - could injure the human brain and nervous system, distress the kidneys and liver, and lead to birth defects. The Minamata disease in Japan between 1954 and 1965; the Love Canal incident, near Niagara Falls in the US; the Koko incident of 1988 in Nigeria; the Thor Chemicals diseases of the early 1990s in South Africa; the disastrous Trafigura dumping of hazardous wastes incident in Ivory Coast, in 2006, are among the numerous pointers to the grave consequences that unscrupulous waste dumping could have on human beings, jeopardizing their livelihood, liberty and very existence. The essence of the above is to demonstrate that the totality of human rights guarantees and particularly the right to life, the right to development, and the entire gamut of economic, social and cultural rights cannot be realized in the absence of the right to a healthy environment.

\section{Current Policy and Legislation and Gaps}

Bangladesh adopted its National Environmental Policy in the year of 1992 for regulation of all activities that pollute and destroy the environment. The Environment conservation act, 1995, with aim to regulate, conserve and enhance the quality of environment and to control, prevent and mitigate pollution. Medical Waste Management Rules, 2008 addressing the waste management issues for the medical sector including E-waste.

The latest initiative is Electrical and Electronic Waste (Management and Handling) Rules, 2011 which has the following features: These rules apply to every producer(s), dealer(s), collection centre(s), refurbisher(s), dismantler(s), recycler(s), auctioneer(s) consumer(s) or bulk consumer(s) involved in the manufacture, sale, purchase and processing of electrical and electronic equipment or components. It defines Responsibilities of the producer, Responsibilities of dealers, Responsibilities of refurbisher, Responsibilities of collection centers, Responsibilities of consumer or bulk consumer, Responsibilities of dismantler, Responsibilities of recycler/ reprocessor.

It describes Procedure for grant of authorization, Power to suspend or cancel an authorization, Procedure for registration/Environmental 
Clearance/Renewal, Procedure for storage of e-waste, Transportation of ewaste, Accident reporting and follow-up, Liability of the producer, collection centre, transporter dismantler and recycler of e-waste, The collection, storage, transportation, segregation, refurbishment, dismantling recycling and disposal of e-waste.

The different schedules of the rules are as Schedule-1 Listing E-waste categories. Schedule-2: Listing the products covered under the categories given in schedule-I, Schedule-3: Deals about threshold limits for use of certain hazardous substances and Schedule-4: Discusses about authorities and corresponding responsibility.

Bangladesh has lack of rules to trade off e-waste and its disposal and management. Bangladesh is a signatory to the Basel Convention prohibiting trans-boundary movement of hazardous waste. Import of any kind of waste requires government permission. There is no comprehensive electronic waste (e-waste) policy, although it is briefly mentioned just as an action item in the country's ICT policy. The government established the Department of Environment (DoE) in 1977 under the Environment Pollution Control (EPC) Ordinance, 1977. Then in 1989, as pollution and environment got more attention, the Ministry of Environment and Forest was established as the apex body. The National Environmental Policy, highlighting the regulation of all activities that pollute and destroy the environment, came into effect in 1992. The subsequent Environment Conservation Act (ECA), 1995, authorized the DoE to undertake any activity necessary to conserve and enhance the quality of the environment and to control, prevent and mitigate pollution. The DoE was also mandated to give clearance on environmental issues for any new project. The subsequent rules under the ECA, the Environment Conservation Rules of 1997, divided industries and projects into different categories depending upon the pollution load and likely impact on the environment. There are some provisions and mandatory rules to build a waste management system within the industry sectors. However, e-waste does not require any compliance under the Act or Rules. The government is now preparing a solid waste management policy which may cover e-waste. At the same time, the Medical Waste Management Rules, 2008, address waste management issues for the medical sector, including e-waste.

\section{Confrontation of E-waste}

The e-waste development trends indicate that a key advantage of Bangladesh is the development of e-waste related policy including waste reduction initiatives such as Extended Producer Responsibility (EPR). This legislation provides Bangladesh with the policy framework to tackle e-waste 
issues in a formal manner as well as fast-track the lessons learned from developed countries in e-waste legislation and management. Nevertheless, ewaste policy development may also pose a disadvantage if it is adopted from developed countries without customizing it to local socio-economic conditions and challenges. Furthermore, some developing countries are considering adopting technologies that have been implemented in developed countries where proper infrastructure is in place to manage e-waste. However, the economic, environmental and social situation in a number of these developing countries are different compared to the developed countries, hence, the need for adapting, implementing, and scaling up appropriate technologies that are more suited to the local conditions. This is consistent with studies on applying EPR policies in Bangladesh which have discovered certain challenges and limitations in EPR policy implementation. The first challenge is for the governments to collect funds from producers or imports if the goods are smuggled into the country or if the small shop-assembled products have a large share of the market.

The second challenge is the systems that create incentives for collectors and recyclers to over-report the amount of e-waste collected to gain extra subsidies from the fund. The third challenge is the competition between the formal and informal recycling sector to gain access to e-waste. One of the key areas for consideration is that the role of the informal e-waste recycling sector in developing countries compared to developed countries. This is because the informal sector in Bangladesh is active in the e-waste recycling chain. These informal recyclers are motivated by the precious materials contained in the ewaste stream and its market value. In countries such as Bangladesh, India and China, where significant amounts of e-waste recycling are taking place, informal collectors achieve very high collection efficiencies. In fact informal collection of e-waste does not have any major adverse impacts on the environment. Instead they lead to high collection rates and many economical and social benefits to the poor section of the community. The informal sector is also involved in the second stage of the e-waste recycling chain-dismantling pre-processing. Even here there are no major impacts on the environment; instead there are more economic and social benefits to the poor community. The last stage of the e-waste recycling chain where processes/techniques are necessary to extract the valuable components such as metals is where the current environmental impacts are present. Most of the informal recyclers utilize low efficiency processes resulting in major health and environmental impacts. For example backyard recycling practices (BRT) utilized by informal recyclers to extract raw materials from printed wire boards, wires and other 
metal bearing components have very low material recovery rates and also result in major environmental impacts.

Prohibiting and imposing fines on informal recycling have not helped in countries like Bangladesh. This is due to the fact that informal recycling is undertaken by the poor people and as such the government is unable to impose heavy fines as they cannot pay it. These governments then attempt to regulate the informal e-waste recycling sector by licensing them. However, the effectiveness of such a scheme depends a lot on the responsibility of the disposer of e-waste. The challenge is how to deal with the e-waste disposer who receives more money from unlicensed informal recyclers than from the licensed recyclers. A study argues that generally the disposers of e-waste are relatively richer than the recyclers; hence, the government can afford to place a heavy fine on them. However, the issue is governments of Bangladesh are unable to impose fines on e-waste disposers of developed countries where most of the ewaste originates. A recent study argues that the emergence and growth of the informal sector in developing countries like Bangladesh is the result of intricate interactions between economic incentives, regulation gaps, industrial interdependence and the social reality and prediction that informal sector may remain an influential recycling force for years to come. They suggested the whole informal recycling chain must be thoroughly investigated for which steps are environmentally harmless and should remain and which steps of the material mass flow should be changed for better downstream environmental and recycling performance.

\section{Entanglement of E-waste Policy}

The policy implications of the e-waste development trends for Bangladesh is that e-waste policy makers should cautiously adopt e-waste policy taking into account the local socio-economic conditions and its potential effectiveness in addressing challenges related to the informal sector. E-waste policy makers should consider supplementing legislative instruments with economic and social initiates such as integrating e-waste management as part of a national green growth strategy and integrating strategic environmental assessment (SEA) into the e-waste policy planning process. This would allow Bangladesh to integrate the informal sector into the country's economic development as well as enable positive social benefits to the informal e-waste sector. Furthermore, e-waste policy makers should also consider establishing an e-waste information system (EIS) that forms the foundation for effective decision making related to e-waste issues in the country as well as establishing a phased national e-waste register for the informal sector. This also enables an effective decision support system to 
tackle basic issues related to e-waste flow. The specific solutions recommended for Bangladesh are:

The first recommendation is the integration of e-waste into the national development agenda via policy planning tools such as green economy assessment (GEA) and SEA. The conventional approach of replicating models from developed countries no matter how successful they are in those counties needs to be reexamined as e-waste issues in developing countries are complex and intricately linked to the informal sector as well as socio-economic-political dynamics. Policy planning tools such as GEA and SEA are expected to enhance e-waste integration of stakeholder considerations, green economy credentials and environmental sustainability in e-waste policy development. The GEA is a system of super streaming national economic policies patterns towards sustainable investment, production and consumption so that economic growth results in both environmental and social growth. The GEA is a paradigm shift from the current traditional 'black economy' based on fossil fuels to a 'green economy' based on renewable energy sources and sustainable production and consumption. The application of GEA for e-waste policy planning would provide the opportunity for the e-waste sector to be integrated as part of a national green growth policy where potentially the government becomes the largest investor and consumer of green e-waste infrastructure and products. This may provide the necessary economic incentive signals for a more environmental responsible e-waste production sector once the government becomes the market and driver to green the supply chain.

Furthermore, GEA would enable the rebranding of the e-waste sector from the current polluting image to a more green opportunity reflection of economic growth for Bangladesh. Meanwhile, SEA is a system of incorporating environmental considerations into policies, plans and programmes (PPP). The SEA was initially promoted as an extension of Environmental Impact Assessment (EIA) principles and practice to PPP where it added value by analyzing PPP at an early stage, thus setting the context and framework for EIAs at the Project level. The application of SEA for e-waste policy planning is especially important in the integration of the environmental considerations during the spatial distribution of e-waste infrastructure and facilities at a regional and a national level. This would enable the cumulative assessment and development of cross-sectoral strategies to prevent improper siting and pollution loading on environmental sensitive areas and environmental sensitive receptors based on the existing carrying capacity of the ecosystem. Furthermore, SEA would also enable the formal integration of alternative scenarios and stakeholder participation in e-waste policy planning which may include options on preventive deep structure economic, environmental and social strategies to 
tackle root-cause problems in the current e-waste management situation of Bangladesh.

The second recommendation is the establishment of national e-waste database systems coupled with a decision support system to collate, update and disseminate data and information on e-waste. Typically, developing countries like Bangladesh lack an e-waste database or a one off e-waste inventory is only conducted as part of a development in an international funded study. Nevertheless, without a continual systematic e-waste information system, Bangladesh would be in essence operating blindly as they lack the decision support system to guide e-waste policy development in a sustainable manner. The e-waste database system is expected to function as a virtual knowledge hub for agencies, organizations, industries and stakeholders for the purpose of coming together and building and enhancing knowledge on e-waste.

The third recommendation is the establishment of a phased national informal sector e-waste register with the purpose of registering and formally recognizing and tracking the informal sector. The biggest challenge of the informal sector is, whether small or large scale is their anonymity to the national authorities which then makes management and regulation fuzzy. Previous attempts to use the carrot or the stick in regulating the e-waste sector has proven less than successful as their identity is often obscure and their numbers considerable. Therefore, an e-waste register without imposing conditions in the initial stage is expected to bring the informal sector into the fold of the formal sector via a soft approach without being perceived as antagonistic, but at the same allows the national governments to monitor the activities of these interim informal sectors. Consequently, the functionality of the e-waste register for the informal e-waste sector can be enhanced by designing it to be an initial soft non-threatening initiative coupled with a GEA incentivization to facilitate the move towards registration and semi-formalization as a means to obtain the economic benefits of formal recognition. A similar approach was adopted by the Japanese government for lead acid battery recycling as well as the Malaysian government for partial e-waste recyclers. This is expected to promote the informal e-waste sector for the necessary administrative, economic and social recognition incentives to operate in a environmentally and socially responsible manner. Finally, a key aspect of e-waste policy development for Bangladesh may require a paradigm shift in perception of e-waste from an informal sector's economic, social and environment problems to a perception of e-waste as a potential opportunity for green economy growth and informal sector mainstreaming. 


\section{Way forward to Alternative Strategy and Approach}

The electronic industry has revolutionized the world over last decades as electrical and electronic products increasingly have become an essential part of everyday human life worldwide. While no one can categorically quantify how much electronic wastes are presently being circulated globally or how much of this waste is hazardous, what is definite is that, if not properly managed, electronic wastes have the potential of threatening human health and the environment. Waste experts, as well as industrialists, environmentalists, and governments, increasingly agree that the response is to generate as little waste as possible in the first place, through the related concepts of cleaner production and eco-efficiency. Cleaner production generates less waste, and reuses and recycles more of what it is produced. Eco-efficiency uses fewer raw materials and there is an upward consensus that industrial societies could cut consumption of them by 90 per cent, while still greatly improving living standards. Although a wide range of environmentally-effective technologies are now available to mitigate emissions and provide public health, environmental protection and sustainable development benefits, and commentators readily subscribe to the sweeping measures and standards adopted against the problem of electronic waste in Europe and the US as the pathway to solve the problem in Bangladesh, the capacity of Bangladesh to procure such technologies or the skills to operate and maintain them are limited. It is therefore reasonable to suggest that solving the e-waste problem in Bangladesh must necessarily entail a multi-pronged approach. While many governments in developing countries are increasingly becoming conscious of the crisis of electronic wastes and aiming to tackle it, others have not domesticated the respectively applicable Basel, Bamako, or Waigani treaties as part of their municipal laws. However, for developing countries, it would appear that the 2006 Nairobi Declaration on Environmentally Sound Management of Electronic and Electrical Waste and more recently by the Bamako Declaration on the Environment for Sustainable Development, 2010, would seem to suggest that the challenges confronting the continent is more than what could be sacrificed on the altar of political expediency.

Today, several developing countries including Bangladesh are drawing up policies regarding electrical and electronic equipment; some are focusing on the age of imported electrical and electronic equipment, for example Ghana is considering a ban on electrical and electronic equipment that is older than five years, while Uganda has banned second-hand electrical and electronic equipment from entering the country, while Nigeria is developing its own guidelines to ensure environmentally sound management of e-waste, and is in discussions with a UK-based waste from electrical and electronic equipment 
recycler to establish a facility in Lagos. Nevertheless, global, regional and national policies focusing on banning or regulating imports, or practices such as open burning have so far been weakly enforced, and have not enabled effective and significant management of electronic wastes treatment. Furthermore, transnational export/import tariffs do not make a distinction between secondhand or unserviceable electrical and electronic equipment and brand new electrical and electronic equipment, which complicates the system of restraining or curbing the illegal import of electronic wastes. Perhaps instead of bans on imports and on informal electronic wastes recycling practices, it is being suggested that both should be more efficiently controlled, and that it is especially vital to include the informal sector within decisions and resulting actions. The risks to the environment and human health connected with informal electronic wastes practices within Bangladesh could potentially be reduced significantly through the use of better dismantling methods. With particular regard to electronic wastes, for example, modern recycling plants can recover or re-use equipment material, leaving only a tiny portion as waste. The envisaged future is one in which societies have reduced to a sustainable level the e-waste-related burden on the ecosystem that results from the design, production, use and disposal of electrical and electronic equipment. One further way forward will be to transfer the global problem of e-wastes to the individual scale in order to increase individual involvement. Actions, targeting the different social classes, should be taken to raise awareness levels through the available means. After all, as experiences from Jordan, Thailand, and China show, separating waste at generation sources has proven to be much easier and more cost effective than at later stages.

In terms of regulations, since achieving a complete universal approach to the problem of e-waste is proving to be thorny, Bangladesh should develop its own legal and policy framework on transboundary movements and management of e-wastes similar to the Administrative Measures on Control of Pollution Caused by Electronic Information Products (known as 'China RoHS') of 2006 and the Ordinance on the Administration of the Recovery and Disposal of Waste Electronic and Electrical Products (known as 'China WEEE') of 2009. In policy terms, one path less taken by developing countries is subscription to the Poverty- Environment Initiative (PEI) of the United Nations Development Programme (UNDP) and the UNEP. The PEI supports country-led efforts to mainstream poverty-environment linkages into national development planning and provides financial and technical assistance to government partners to set up institutional and capacity strengthening programmes and carry out activities to address the particular poverty-environment context. Regrettably, less than 50 developing countries are current partakers of this initiative. The above makes it 
critical that approaches and responses to the phenomenon of hazardous electronic wastes begin to integrate proper conceptualization along with the poverty question in many developing countries. Warnings are emerging that global warming, climate change, and depletion of the ozone layer are all indications of the limit of the Earth's capacity to assimilate wastes. These wastes, in whichever form they come, have direct linkages to the desperate quest for survival and livelihood in several countries, developed and developing alike.

While legal frameworks and policy initiatives are indeed veritable components of appropriate responses to the menace of electronic wastes in developing countries like Bangladesh, there is no gainsaying the fact that strategic responses must bring all actors to the table. The bottom-line of the contention here is that all the actors along the product-disposal chain share responsibility for the environmental impacts of the whole product system. The greater the ability of each stratum of actor(s) to influence the environmental impacts of the product system, therefore, the greater the share of responsibility for addressing those impacts should be. The actors contemplated within the framework of this discussion are the product manufacturers, the suppliers, and the consumers. Manufacturers should reduce the life-cycle environmental impacts of their products through their influence on product design, material choices, manufacturing processes, product delivery, product system support, and product disposal mechanisms. Suppliers should have a significant influence by providing manufacturers with environmentally friendly materials and components. Consumers should affect the environmental impacts of products in a number of ways, namely, by way of purchase choices (i.e. choosing environmentally friendly products), adopting good maintenance culture and environmentally-conscious operation of electronic products, and careful end-oflife disposal special care in disposing of household electronics containing toxic substances and returning them to proper facilities where possible.

\section{Conclusion}

Solid waste management, which is already a big challenge for Bangladesh, is becoming more complicated by the invasion of e-wastes. There exists an urgent need for a detailed assessment of the current and future scenario including quantification, characteristics, existing disposal practices, environmental impacts etc. Institutional infrastructures, including e-waste import, collection, transportation, treatment, storage, recovery and disposal, need to be established, at national and/or regional levels for the environmentally sound management of e- wastes. Establishment of e-waste collection, exchange 
and recycling centers should be encouraged in partnership with private entrepreneurs and manufacturers. E-waste policy development may require a paradigm shift in perception from a problematic waste issue to a opportunistic green growth solution for Bangladesh. Consequently, this paper suggest that ewaste policy development may require a more customized approach where instead of addressing e-waste in isolation it should be addressed as part of the national development agenda that integrates GEA and SEA as part of national policy planning.

\section{References}

Ahmed FRS (2011) E-waste management scenario in Bangladesh. In: WEEE/E-waste management workshop on take-back system, pp 13-15

Akenji L, Hotta Y, Bengtsson M, Hayashi S (2011) EPR policies for electronics in developing Asia: an adapted phase-in approach. Waste Manage Res 29(9):919-930

Agamuthu P, Victor D (2011) Policy trends of extended producer responsibility in Malaysia. Waste Manage Res 29(9):945-953

Arora R, (2008), Best Practices for e-waste management in developing nations, Europe Aid Co-operation Office, pp 1-24.

Babu, B. R., Parande, A. K., \& Basha, C., A. (2007). Electrical and electronic waste: a global environmental problem. Waste Management \& Research, 25(4), 307-318

Barba-Gutierrez, Y., B. Adenso-Diaz, et al. (2008). "An analysis of some environmental consequences of European electrical and electronic waste regulation." Resources. Conservation and Recycling 52(3): 481-495.

BAN (Basel Action Network) (2006): A Call for an Interpretation of Article 17 by the Parties for Rapid Entry into Force of the Basel Ban Amendment. [Online], available at: http://www.ban.org/ Library/ban_entry_into_force_06.pdf [accessed on 10 March 2015]

Basel Secretariat (2009): List of possible reasons discussed at the first meeting of the CLI [online], available at: http://www.basel.int/convention/cli/index.html [accessed on 7 March 2015]

Brigden K, Labunska I, Santillo D, Allsopp M (2005) Recycling of electronic wastes in China and India: workplace and environmental contamination. Greenpeace International, $\mathrm{p} 55$

Chatterjee S, and Kumar K, (2009), Effective electronic waste management and recycling process involving formal and non-formal sectors, International Journal of Physical Sciences, 4(13), pp 893-905.

Chung S (2012) Projection of waste quantities: the case of e-waste of the People's Republic of China. Waste Manage Res 30:1130-1137

Dennis V, Agamuthu P (2012) Strategic environmental assessment policy optimization prospects for solid waste management in Malaysia. Presented at the International Solid Waste Association World Congress, Italy, 2012, Florence, Italy 
Department of Environment, Malaysia (2006) The e-waste inventory project in Malaysia. Department of Environment, Malaysia

Gibson K, Tierney JK (2006) Electronic waste management and disposal issues and alternatives. Environ Claims J 18(4):321-332

Gottberg A., Morris J., Pollard S., Mark-Herbert C. and Cook M. (2006), Producer responsibility, waste minimisation and the WEEE Directive, Case studies in ecodesign from the European lighting sector, Science of the Total Environment, 359, pp 38-56.

Herat S (2008) Green electronics through legislation and lead free soldering. CLEAN Soil Air Water 36(2):145-151

Huisman, J., \& Stevels, A. (2004). Eco-efficient implementation of electronic waste policies in practice. Electronics and the Environment Conference Record for 2004 IEEE International Symposium, pp. 243-248.

Kahhat, R., Kim, J., Xu, M., Allenby, B., \& Williams, E. (2008). Proposal for an ewaste management system for the United States. IEEE International Symposium on Electronics and the Environment Year, pp. 1-6

Kojima M, Yoshida A, Sasaki S (2009) Difficulties in applying extended producer responsibility policies in developing countries: case studies in e-waste recycling in China and Thailand. J Mater Cycles Waste Manage 11(3):263-269

Lindhqvist Thomas. (2000). Extended Producer Responsibility in Cleaner Production. Policy Principle to Promote Environmental Improvementsof Product Systems, IIIEE Dissertations 2000:2. Lund University, the International Institute for Industrial Environmental Economics: Lund.

Manomaivibool, Panate. 2009. Extended producer responsibility in a non-OECD context: The management of waste electrical and electronic equipment in India. Resources, Conservation \& Recycling, 53 (3): 136-144.

Mo, H., Wen, Z., \& Chen, J. (2009). China's recyclable resources recycling system and policy: A case study in Suzhou. Resources, Conservation and Recycling, 53(7), 409-419

Nnorom, I. C. and O. Osibanjo (2008). "Overview of electronic waste (e-waste) management practices and legislations, and their poor applications in the developing countries." Resources. Conservation and Recycling 52(6): 843-858.

Robinson, B., H. (2009). E-waste: An assessment of global production and environmental impacts. Science of the Total Environment, 408(2), 183-191

Schmidt, M. (2005). A production-theory-based framework for analysing recycling systems in the e-waste sector. Environmental Impact Assessment Review, 25(5), 505-524

Sthiannopkao S, Wong MH (2012) Handling e-waste in developed and developing countries: Initiatives, practices, and consequences. Sci Total Environ, Aug

Terazono A, Murakami S, Abe N, Inanc B, Moriguchi Y, Sakai S, Kojima M, Yoshida A, Li J, Yang J (2006) Current status and research on E-waste issues in Asia. J Mater Cycles Waste Manage 8(1):1-12 
United Nations Environmental Programme (2007) E-waste volume II: e-waste management manual. Division of Technology, Industry and Economics, International Environmental Technology Centre, Osaka

Wagner, T.P. (2009): "Shared responsibility for managing electronic waste: A case study of Maine, USA", in: Waste Management 29, 12, pp. 3014-3021.

Widmer, R., Oswald-Krapf, H., Sinha-Khetriwal, D., Schnellmann, M. \& Boni, H. (2005). Global perspectives on e-waste. Environmental Impact Assessment Review, 25(5), 436-458

Yoshida, Aya, Tasaki, Tomohiro and Terazono, Atsuhi. 2008. Estimation of Secondhand Personal Computer Import and Export in Asian Region. IEEE Xplore. Downloaded 14 January 2009.

Xianbing, L., Masaru, T., \& Yasuhiro, M. (2006). Electrical and electronic waste management in China: progress and the barriers to overcome. Journal of Waste Management \& Research, 24(1), 92-101. 